\title{
Planet, Ethics, Health and the New World Order in Proteins*
}

Sylvain Charlebois (Corresponding Author), Simon Somogyi, Janet Music, Isabelle Caron

Agri-Food Analytics Lab, Faculty of Management/Factulté De Management, Kenneth C. Rowe Management Building, Room 3057, 6100 University Avenue, PO Box 15000, Halifax

NS CANADA B3H 4R2. Email: sylvain.charlebois@dal.ca

Received: Dec. 20, 2019

doi:10.5296/jas.v8i3.16535
Accepted: Jan. 19, 2020

Published: Feb. 26, 2020

URL: https://doi.org/10.5296/jas.v8i3.16535

\begin{abstract}
While meat consumption is increasing in the developing world, it has plateaued in many developed economies. Optimal for health and projected trends suggest global meat consumption is set to rise further into this century, but not everywhere, especially in the Western world. Plant-based dieting appears to be taking a larger place in how consumers view food systems in developed economies. The aim of this exploratory study is to better understand consumer attitudes about meat consumption and assess the intersections between meat avoidance and attachment. It also investigates how prominent plant-based, or self-imposed dietary restrictions related to meat consumption are in the marketplace. Results show that a significant number of Canadians have adopted a diet which either limits or eliminates the consumption of meat. Some generational differences were reported. While many vegans are under the age of 38 (Millennials and Gen Zs), a great number of boomers consider themselves as flexitarians. Health benefits appear to be important for both genders. Women appear to be more concerned about animal welfare and taste preferences. Some limitations are presented, and future research ideas are put forward.
\end{abstract}

Keywords: meat consumption, meat avoidance, meat attachment

\section{Introduction}

Meat protein has traditionally been an important part of consumer's diets. While meat consumption continues to rise in the developing world, it has plateaued in many developed economies. In Canada, for example, beef consumption has decreased by $16 \%$ since 2010 (Statistics Canada, 2017). Annual demand for beef has decreased by 94 million kilos (Canada

*Prepared for presentation at the Alberta Institute of Agrologists 16th Annual General Meeting and Conference, Banff, Alberta, April 2020 
Newswire, 2018), leaving Canadian meat producers with a shrinking domestic market. Overall, though, projected trends suggest global meat consumption is set to rise well into this century (Bailey et al., 2014; Charlebois, McCormick and Juhasz, 2016). Conversely, plant-based dieting appears to be gaining traction among Western consumers. Certainly, plant-based diets can offer similar health benefits in terms of protein intake compared meat consumption. The underlying motivations for consumers to switch to plant-based diets are not well known. Indeed, some have argued that adopting a plant-based diet is a result of lifestyle choices, more so than restrictive dieting based on nutrition (Stranieri, Banterle and Ifama, 2015).

With population growth expected to reach 8.5 billion by 2030, 9.7 billion by 2050 and 11.2 billion by 2100 (United Nations Department of Economic and Social Affairs, 2015), significant pressure will be placed on food systems around the world. The Food and Agriculture Organization of the United Nations (FAO) (2012) has stated that in order to be sustainable, diets must be protective and respectful of biodiversity and ecosystems, culturally acceptable, accessible, economically fair, and inexpensive; nutritionally adequate, safe and healthy; while optimising natural and human resource. Reconciling sustainable diets with meat consumption becomes important, as the amount of resources needed to produce meat can be substantial. Livestock production is a major contributor to greenhouse gas emissions (O’Mara, 2011; Beauchemin, Janzen, Little, McAllister, \& McGinn, 2010). In addition, the water footprint per gram of protein from red meat is estimated to be six times larger for livestock than for pulses (Janzen, 2011). Research suggests that meat plays an emotive role in lifestyles; despite scientific evidence connecting meat consumption with anthropogenic climate change, consumers show significant meat attachment (de Boer, Schösler, \& Boersema, 2013; Macdiarmid, Douglas, \& Campbell, 2015; Charlebois, Somogyi and Kirk, 2019).

Meat preference is part of the North American cultural landscape. Meat is lionized in popular culture (Chiles and Fitzgerald, 2018), and is an important part of agrifood business. However, recent studies have shown a shift towards meat avoidance among a growing number of consumers (Neff et al., 2018; Charlebois et al., 2019). Indeed, the United States (US) has decreased the amount of meat they consume by 4.3k/per capita (OECD Agriculture Statistics, 2018). During the same period, Canadians have reduced their red meat intake by $5.7 \mathrm{k} / \mathrm{per}$ capita (OECD Agriculture Statistics, 2018). While meat consumption is slowing among the general population, research has shown that $9.4 \%$ of Canadians identify as vegetarian (Charlebois et al., 2019). This is an increase from a 2003 survey by American Dietetic Association and Dietitians of Canada that suggested that $4 \%$ of Canadians self-identify as vegetarians.

The underlying motivations of Canadians that decrease their meat consumption remains unclear. Common factors for dietary changes include cost, health concerns and weight control (Frenette, Bahn and Vaillancourt, 2017). To a lesser extent, consumers cite moralistic values as a pathway to meat reduction. A recent study of US consumers indicated that $50 \%$ of those who had reduced their meat intake did so because of health concerns, while only $12 \%$ cited animal welfare as the driver of reduction (Neff et al. 2018). A 2018 market research study in the UK found that $31 \%$ of respondents were reducing meat for ethical or health concerns 
(Compare the market, 2018). Whether or not these findings are comparable in the Canadian context is unknown.

A significant portion of the Western population is reducing their meat consumption; however, more information is needed on the Canadian market, consumers' motivations underpinning meat reduction and consumer views on meat as part of their dietary needs. There is some evidence to suggest that US consumers exhibit strong meat attachment (Amiot et al., 2018). However, meat attachment in the Canadian context is yet to be determined. Understanding which divergent demographic groups exhibit meat attachment is important for policy makers targeting overall population health as well as driving economic stability among agrifood producers. According to a 2015 study, Statistics Canada found that Canadians view red meat as an important part of their dietary intake, consuming 61 grams per day on average, though this is a reduction from 75.3 grams per day consumed on average in 2004 (Canadian Community Health Surveys (Nutrition), 2015). Clearly there is a need to recognize the pathways to meat reduction.

The aim of this exploratory study is to better understand consumer attitudes about meat consumption and the nexus between avoidance and attachment in the Canadian consumer. It also investigates how some factors motivate consumers to eat or avoid meat altogether. The study looks at both the rejection and hedonism of meat consumption as axes to assess the interplay between the two. We analysed the determinants that lead consumers to make different choices around meat consumption, health, environment, animal welfare and the socioeconomics of meat.

\section{Meat Attachment and Avoidance}

Throughout human history meat has been considered a viable source, often the only source, of protein (Chiles and Fitzgerald, 2018). As a quasi-cultural and a socio-economical object, meat has traditionally carried various symbolic meanings such as status, power, and privilege (Charlebois and Labrecque, 2009; Pohjolainen, Vinnari and Jokinen, 2015). Historically a scarce but cherished food in the Western world, a growing number of populations with lesser means shifted towards eating meat and animal-based products in general, and a decreased consumption of grain and plant-based foods. As countries experience wealth, they gravitate naturally towards animal proteins. Meat attachment has been measured in past studies (Graça, Calheiros and Oliveira, 2015). For the purposes of this study, hedonism refers to the pleasure of eating and celebrating meat as explored by Verbeke (2014), who has discussed the affinity for meat products, entitlement of being a meat eater, and the perception of being dependent of animal proteins. Awareness of dietary needs, and knowledge of nutritional options can influence dietary habits that extend beyond meat as a source of dietary protein. Types of meat products, price and fat content labels have been found to have great influence on consumers (Apostolidis and McLeay 2019). These features have been found to have great influence on consumers. 


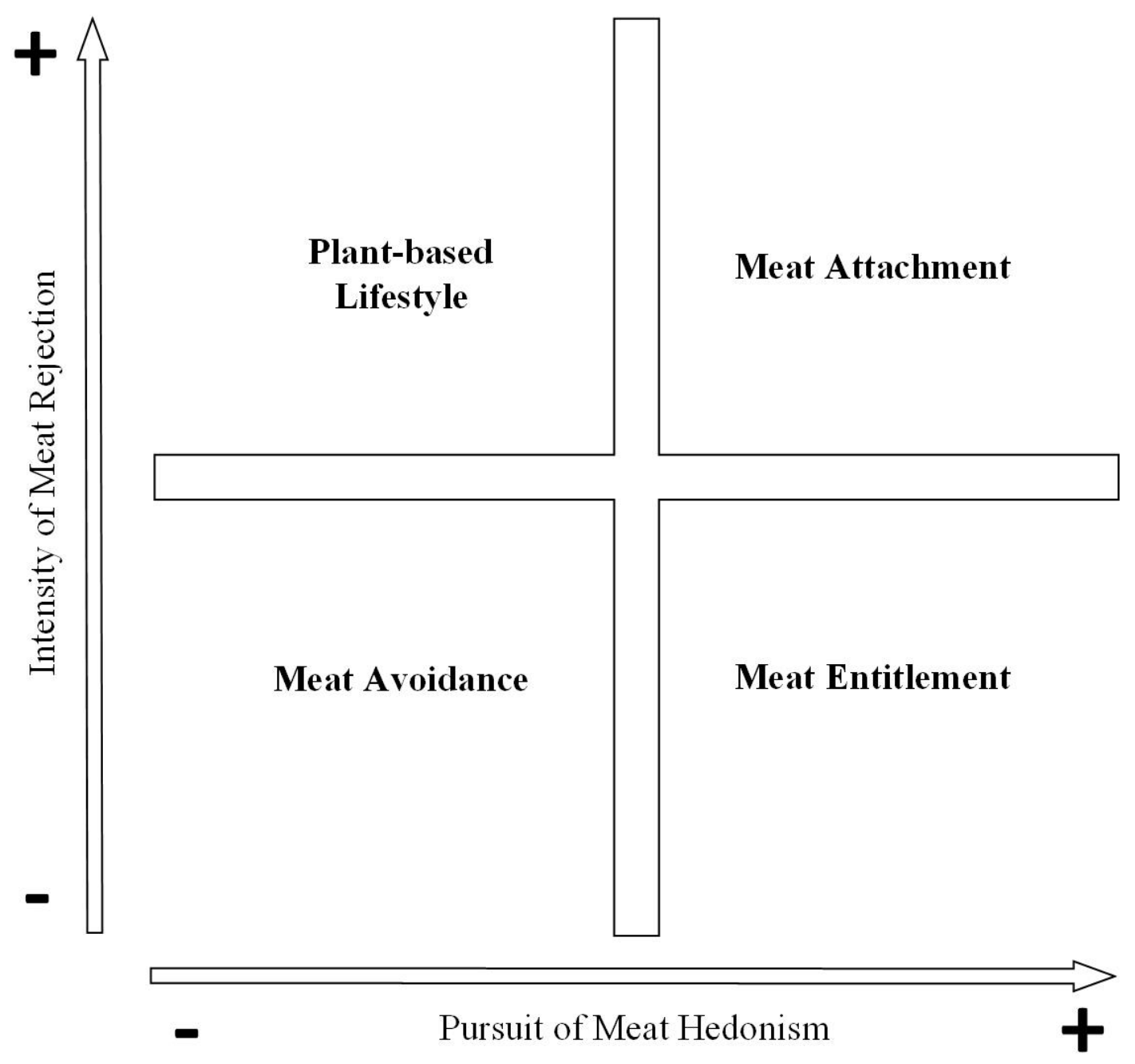

Figure 1. Interplay between dimensions of meat consumption preferences

Suggesting consumers eat less meat may trigger resistance to change. Indeed, consumers may exhibit confusion regarding amounts and sources of protein to sustain a healthy diet. Certain consumers resist plant-based dieting as a lifestyle or an option. Meat consumption often triggers highly ambivalent feelings. On the one hand, it is associated with sensory pleasure and tradition; on the other hand, it is linked to moral, ecological, and health-related issues, also known as a meat paradox (Charlebois, Von Massow and Pinto, 2015; Buttler and Walther, 2018). Interestingly, the blockade effect seems to be linked to masculinity, traditionalism, and hierarchies, all of which resemble and maintain the conventional structures of power in the West (Hildén, Jokinen and Aakkula, 2012). Such influences also resemble the symbolic and social history of meat consumption. Conversely, urbanization, increased access to education for all and a rising female voice are distinctively products of modern society and thus push for cultural change. These social determinants may lead to decrease meat consumption in the future (Beardsworth and Bryman, 2004; Latvala et al., 2012; Graça, Godinho, and Truninger, 2019). The quest for more diversity has also opened the door to a more diverse set of values 
embedded in food systems we rely on in order to survive and co-exist with nature.

\section{Research Methods}

Data was gathered by using an online survey conducted nationally across Canada. The survey instrument was adapted to cover measures created from Graça, Calheiros and Oliveira's 2015 study on meat hedonism as mentioned above, as well as new questions on protein substitutions. The exploratory nature of the study allows for a better understanding of how consumers are either avoiding meat products or remain attached to them. The intent is to measure how pluralistic proteins have become in the Canadian marketplace.

Steps were made to ensure a mixed approach combining a social constructionist and a positivist framework in generating items relevant to the study of meat attachment. Qualtrics research firm hosted the survey online both French and English in September 2018. Qualtrics utilizes a panel of Canadian consumers consisting of over 1.3 million members. This study was conducted through an accessible e-platform to capture a full and accurate reflection of the Canadian market. To correct for sampling bias and non-response bias in some remote regions, the survey targeted respondents by age and gender within region. Based on the sampling design, the margin of error is $3.1 \%, 19$ times out of 20. The performance of this survey is consistent with other similar surveys on perceptions in food (Barcellos et al., 2015).

Ethical approval to conduct the survey was granted by Dalhousie University's Research Ethics Board in accordance to the Tri-Council Policy Statement: Ethical Conduct for Research Involving Humans. The research did not involve deception, however, to minimize self-selection biases, no references were made in the advertisement and cover page to the specific goals of the study. All participants were offered the opportunity to receive summary results of the study if they supplied an email address.

The survey was administered to 1029 randomly selected adult Canadians with a response rate of 94\%. All respondents have lived in Canada for twelve months and are least 18 years of age, in accordance to the standards of research conducted with minimal risk. To obtain an effective measuring tool a pre-test was piloted prior to the official survey launch to ensure that the questions were understood clearly. The pre-test involved approximately 50 respondents to confirm that the instrument was operating correctly. Incomplete responses were removed from the dataset. All questions were also translated into French and therefore the meaning and tone for these questions needed to be adjusted and verified through the pilot test. Results from the pre-test suggested that usability and readability were sound and that the survey took no longer than 10 minutes to complete.

The survey instrument was structured in five parts (see Appendix A). First, we questioned respondents about their meat consumption in general. This included frequency of consumption and self-identified dietary preferences. Food categories were purposefully defined broadly as meat, seafood, plants and dairy. This allowed respondents to use their own frame of reference for food without introducing bias. Largely inspired by Pohjolainen, Vinnari and Jokinen (2015), and Graça, Calheiros and Oliveira (2015), the second portion of the survey examined meat consumption trends over time. Respondents were queried about 
their intentions to reduce meat in their diet. Respondents that have reduced meat or were thinking about reducing meat soon were questioned regarding the underlying causes for this decision. Questions were designed based on past meat avoidance studies like Beardsworth and Bryman (2004), and Buttlar and Wathler (2018, 2019). These included six commonly reported reasons for exclusion within a given diet: animal welfare, cost, environmental concerns, health, taste, and weight control (Curtis et al., 2014). The third portion of the survey instrument assessed how attached consumers are to meat consumption. Meat attachment was determined through a series of questions using a 5-point Likert scale during which respondents reported their attitudes towards meat. Respondents who reported 'agree' or 'strongly agree' with positive attitudes toward meat consumption were considered to have high meat attachment or hedonism toward meat consumption. Those respondents that responded 'disagree' or 'strongly disagree' with positive attitudes towards meat were considered to have avoidance and rejection. The fourth section of the questionnaire considered meat avoidance. These measurements explored how hedonism and avoidance are critical for all demographic groups represented. Finally, the questionnaire probed meat substitution awareness and measured how the conceptual framework can apply to meat consumption trends in Canada.

\section{Analysis}

As this is an exploratory study, the intent is to establish priorities for further research on Canadian consumers' attitudes towards meat consumption. To do so, we performed descriptive analysis on demographic variables using Excel and proprietary software designed by Qualtrics. Respondents were asked a series of demographic questions in order to better understand regional, gender, age, education, income and household variations within the data. Using these demographic indicators, we determined statistical significance among demographic groups of self-identified dietary profiles, motivations underpinning meat reduction as well as meat attachment, avoidance and hedonism.

\section{Results}

\subsection{Meat Consumption Frequency}

The survey garnered interesting results. Table 1 describes sample demographics overall by self-reported dietary identity. In regard to meat consumption respondents were asked how frequently they consumed meat products. Canadians eat meat regularly. More than $48 \%$ of respondents stated that they consume meat daily. More than $40 \%$ stated that they consumed meat once or twice a week. The results on dietary choices confirmed that Canadians were reducing their meat intake. While $82.1 \%$ of respondents stated that they do not have any dietary restrictions, more than $10 \%$ considered themselves flexitarians (see Figure 2). Other options garnered less than a $2 \%$ response rate (see Figure 2). Results suggest that over 6.4 million Canadians follow a diet, which either restricts or eliminates the consumption of meat products. 


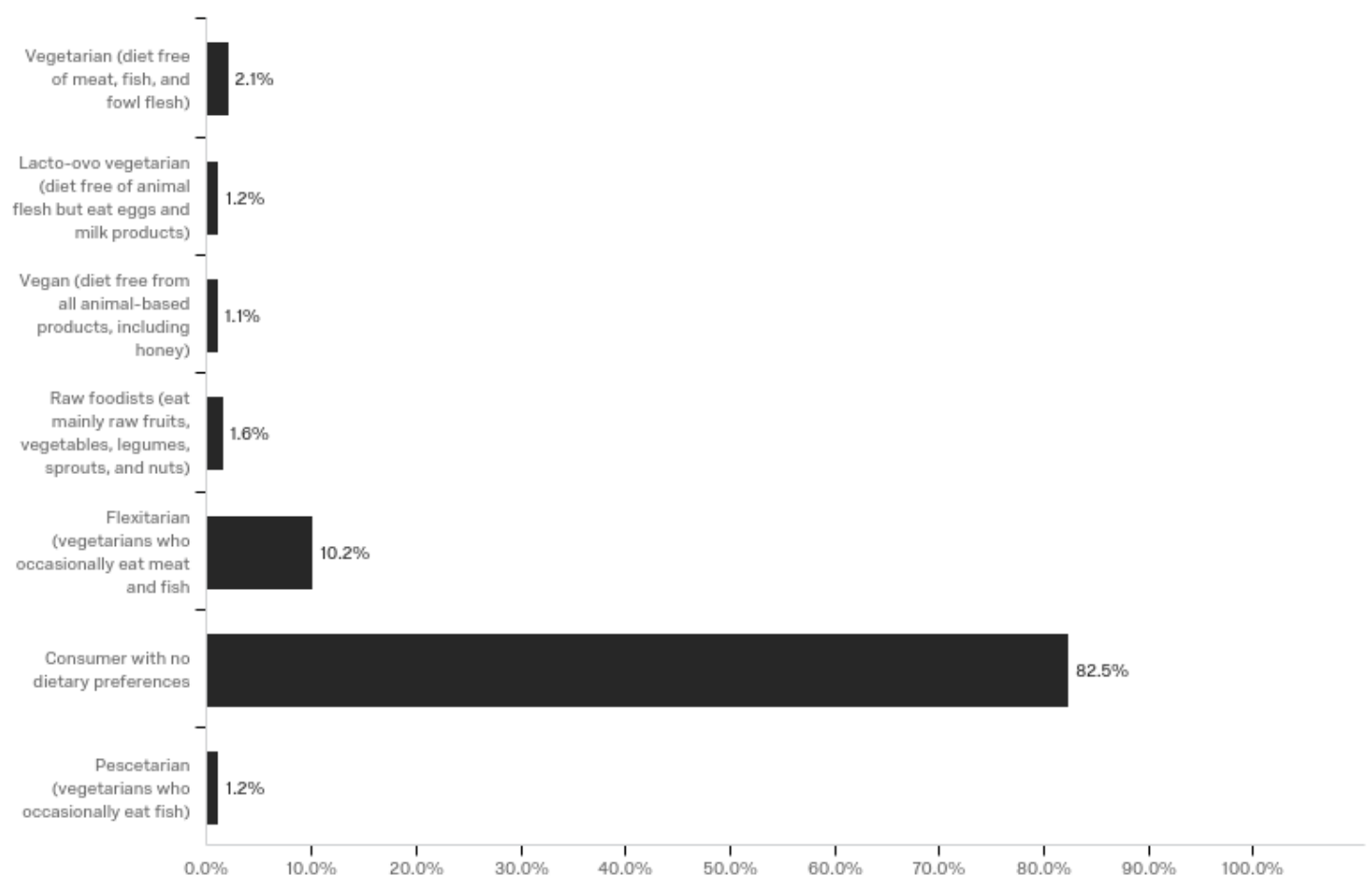

Figure 2. Title

Some generational differences were identified. $63 \%$ of vegans are under the age of 38 (Millennials and Gen Ys), and $42 \%$ of flexitarians are Boomers. $46 \%$ of respondents who reduce or eliminate their consumption of meat products live in the province of Ontario. According to the survey, most Canadians have thought of reducing their meat consumption, and $32.2 \%$ of respondents intend to reduce their meat consumption within the next 6 months (see Figure 3). Level of education affected respondents' intent to reduce meat consumption. Results suggested that consumers with graduate degrees are more likely to want to reduce meat consumption over the next 6 months. Results also show that consumers earning between $\$ 75,000$ and $\$ 99,999$ appear to want to reduce meat consumption over the next 6 months, more than other groups. 


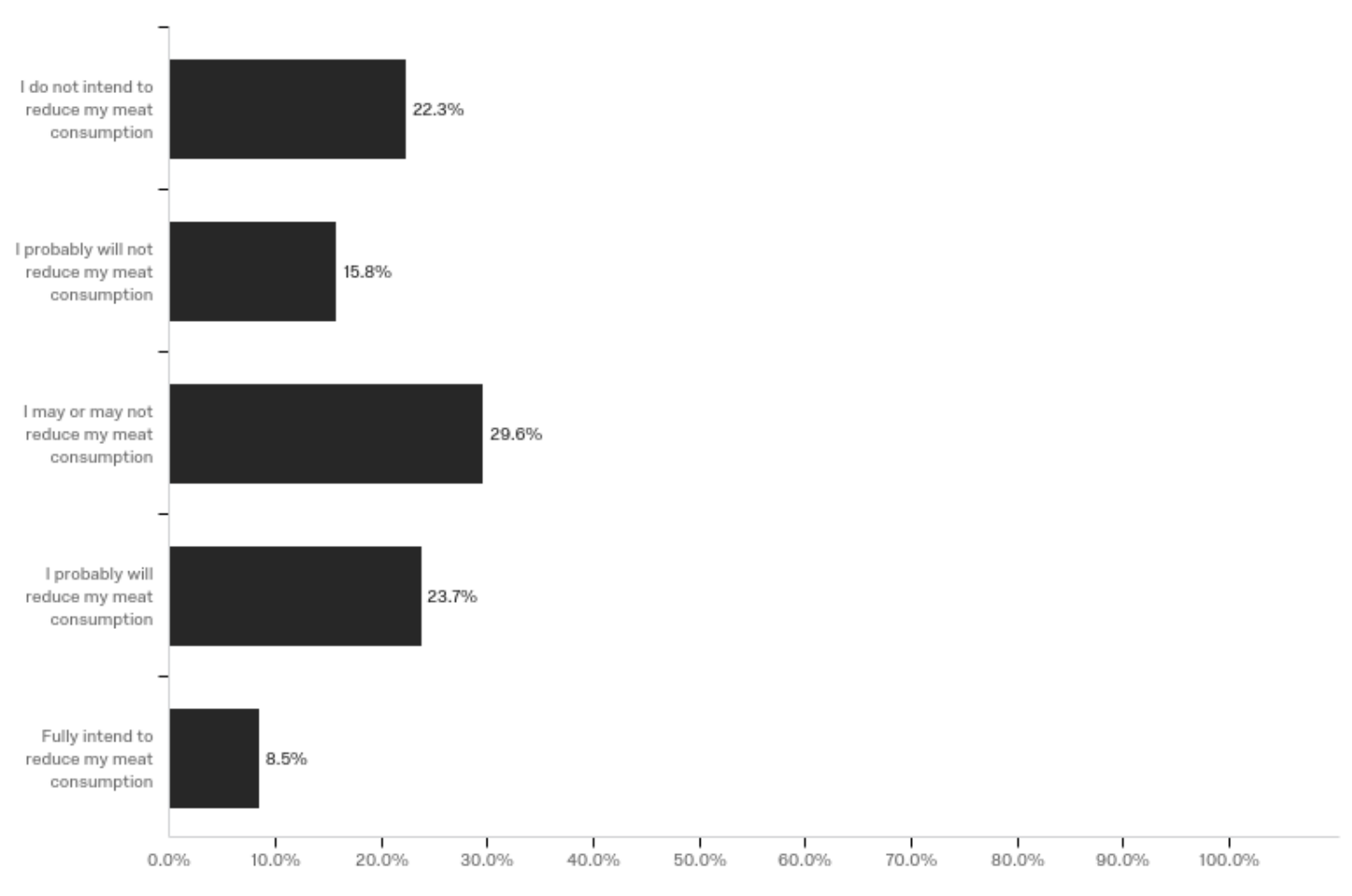

Figure 3. Title

\subsection{Meat Reduction}

The survey also looked at determinants that could motivate respondents to consider alternative sources of proteins. Two determinants highlighted that gender and the number of children in households are motivators for considering alternative sources of proteins. All other determinants offered mixed results. For these, it appears that health benefits appear to be important for both genders. Women appear to be more concerned about animal welfare and taste preferences. Other factors generated mixed results. More than half of households with three children or more appear to be more influenced by taste preferences, while more than half of households with two children are concerned about health benefits.

\subsection{Meat Attachment}

Meat attachment and appeal was also measured during this survey. A series of questions related to the attachment were posed in order to measure sentiments and feelings. Results show that men are more likely than women to consider eating meat as a great pleasure in life. However, younger and more educated respondents are less likely to enjoy meals with meat. Men who are less educated are more likely to see themselves as big fans of meat. In addition, younger consumers are less likely to believe that eating meat is a fundamental right. Interestingly, most women consider eating meat as part of a natural and balanced diet. This point may suggest that women consider the result of meat consumption as more significant than the experience. Generally, older respondents are more likely to see themselves as meat eaters and as a source of enjoyment. 


\subsection{Meat Substitution}

The last section of the survey was about substitution and possible alternatives. The survey explored respondents' awareness of alternatives. Women appear to recognize substitutes for meat more so than men. Results also suggest that women know how to replace animal proteins from diets, more so than men. We also explore the option of alternative sources of protein beyond vegetables. The survey asked about lab-grown culture and insects. It appears respondents in Atlantic Canada and Quebec are more open to consider insects as an alternative, but the interest was considered as insignificant. As for lab-grown meat, the support was higher. In fact, younger respondents appear to be more receptive to lab-grown meat.

Results suggest that respondents may see themselves in more ways then one. It appears Canadians are increasingly going meatless as this study estimates over 6.4 million Canadians have dietary preferences, which reduces or eliminates meat consumption. This number is higher than predicted, as $32.2 \%$ of Canadians are thinking of reducing their meat consumption over the next 6 months. In total, $63 \%$ of Vegans in Canada are under the age of 38 , and $42 \%$ of Flexitarians are Boomers. This suggest that the number of Canadians who will reduce the amount of meat they consume will only increase over time. Despite this movement, a significant number of Canadians remain attached to meat, for one reason or another. The interplay between meat attachment and avoidance is compelling many to redefine themselves as meat or non-meat eaters. Results show that respondents see themselves in many different ways when considering their relationship with meat.

\section{Discussion}

This exploratory study demonstrates that the Canadian market for proteins is slowly changing. This unique study provides a substantial amount of evidence to support claims that Canadians are increasingly revisiting their relationship with animal proteins even if Canada is known for its meat-eating culture. To our knowledge, this is the first time a study has looked at how protein demand is changing in Canada, a country where meat-eating is very much part of culinary traditions.

Among those respondents have no dietary preferences almost $18 \%$ see themselves as following a specific diet that limits or eliminates the amount of meat consumed. That equates to about 6.4 million Canadians who are following a special diet in relation to meat consumption. A total of $63 \%$ of respondents who consider themselves as vegans or vegetarians are under the age of 38 , which would include respondents who identified themselves as members of the Gen $\mathrm{Z}$ or Millennials group. Almost a third of respondents claimed that they were planning to reduce their meat consumption within the next 6 months. The interplay between meat rejection and the pursuit of meat consumption is creating tensions within the Canadian population. On the one hand, men with a lower education appear to be more attracted to meat consumption and see meat consumption as a right, a pleasure of life and means for survival; whereas other demographic groups are slightly or significantly more attracted to a different lifestyle, or a diet which includes little or no meat. These findings are consistent with studies conducted in the past (Oats, Cohen and Brown, 
2012; Stubbs, Scott and Duarte, 2018). Other demographics, including women, younger respondents, and higher educated respondents, appear to be attracted to the concept a meat avoidance and the outright rejection of meat. But overall results do not suggest Canadians are rejecting meat as part of their diets. Observing high levels of overall meat consumption acceptance amongst certain demographics simultaneously with high percentages of respondents wanting to avoid meat consumption could be a "meat paradox", as suggested by Buttlar and Walther (2018). Cultures, eras, and values collide as we witness a growing number of consumers questioning the source, and even existence of certain agri-food production models. Based on our survey results, this trend may increase as younger respondents are concerned about social, environmental and health dimensions of meat production and consumption. Baby Boomer respondents yielded surprising results in identifying as flexitarians. A total of $42 \%$ of flexitarians are Boomers, which may indicate that some respondents grew up in an era of irregular meat consumption due to scarcity, religious adherence or cost.

The present study has theoretical implications. Although existing literature describes vegans and vegetarians as "sustainable consumers", this study suggests that consumers may be of two minds when considering meat as a protein source option. This study is country-specific, and only looks at the Canadian landscape. As many other mature and industrialized markets, meat plays an important role in consumers' culinary and food traditions (Nasser et al., 2009; Charlebois and Haratifar, 2015). Few studies have looked at how a mature meat market can change, or how it is changing by specifically looking at the duality between meat avoidance and attachment. The meat paradox, a well-researched concept, looks at factors influencing behavior. The study of the avoidance/attachment evolutionary fusion considers the modern pluralistic reality of protein sources. Meat consumption, once capped, can look beyond animal proteins and look at the coexistence of several sources of proteins.

The study was designed to reveal how respondents, regardless of dietary identity, view consuming animal proteins. These factors are equally important in informing the dietary choices of flexitarians as well as other dietary demographic groups. However, for flexitarians, the environmental and social considerations appear to outweigh other factors such as health or cost in their choices to reduce the quantity of meat they consume. For all respondents, food choices and dietary patterns have developed in the context of our modern economy. The idea, perhaps, is that a large group of consumers practicing flexitarianism could have a greater positive effect on climate and public health consequences of meat consumption than a small number of individuals practicing strict vegetarianism or veganism. After the emergence of the word flexitarianism, between 2005 and 2007 (Dilthworth and McGregor, 2015), the term evolved from a definition of a vegetarian consumption options which indicates that consumers want to be mindful of their food choices and mitigate risks for the longer term without compromising culinary luxuries. It is also interesting to notice that those considered middle class are more willing to reduce their meat consumption than other groups. When assessing factors, health is the most dominant driving factor, which is making respondents think differently about meat consumption.

Some managerial implications ought to be considered. The findings of our study suggest that 
meat reduction campaigns should include targeting the cultural aspects of meat reduction. That is, to impact those female consumers willing to reduce meat intake, animal welfare and environmental sustainability of producing meat should be stressed. Of interest from these research findings is the cultural identity that many men in different demographic sections feel with meat, or their degree of meat hedonism. This suggests that simple information campaigns based on animal welfare, environmental sustainability, or health indicators alone may not be enough to sway sub-segments of the population away from meat consumption. For meat producers, connecting with men's identity as meat-eaters is advantageous for to maintain continued market share.

To our knowledge, this is the first study to recognize meat attachment among demographic segments of the Canadian consumer society. The study uses a rigorous, nationally representative sample frame with detailed questions posed to uncover the level of meat attachment and the underlying motivations for meat rejection among Canadian consumers.

There are limitations to this study, however. While the study purposefully left the definition of meat vague in order to allow respondents to answer based on their own interpretations, this may indicate overlap among self-identified dietary preferences. For example, one respondent may not consider eggs as part of a meat group, and may include them in a vegetarian diet, while another would consider egg consumption as part of a lacto-ovo, vegetarian diet. In addition, the questionnaire did not delve into individual diets of self-reported dietary identities. Studies suggest that individuals do not accurately self-report when it comes to dieting (Thompson and Subar, 2017). Therefore, without this information, the researchers were unable to validate some responses. Finally, details on meat reduction asked about meat in general and not about specific types of meat, making a more granular analysis on which meat is being reduced, or the amount of meat reduced each meal, difficult to prove with our results.

Meat production is an important part of the Canadian economic portfolio. Indeed, as meat remains a stable and important part of many consumer's daily die in the country, the economic repercussions of reduced meat consumption remain low. However, recent policy changes highlighting the promotion of plant-based dieting by Health Canada signal a shift that recognizes reduced meat protein as beneficial for health and longevity. This study has shown that enticing Canadians to change their diets based on health indicators alone may not be enough for some demographic segments of society.

The conceptual framework presented is this study's greatest contribution. The two axes, intensity of meat rejection versus meat hedonism are spectrums which can create frictions between meat consumers and meat avoiders. The four quadrants have never been presented and explored before. This is the first study looking at all four dimensions of protein consumption. Each quadrant deserves more attention in future studies, and, the plant-based diet and meat entitlement quadrants. We can postulate that the same consumer, the same person, can go from one quadrant to another, depending of needs, wants, and effects of other factors measured in this study over a short period of time. Consumers can change behavior, make different, inconsistent choices from one meal to another. This study goes beyond 
dietary labels and look at how respondents view proteins, holistically. As protein consumers, we all can fit in one quadrant, or mix two, perhaps three quadrants over a short period of time. In an era in which we can easily categorize diets and eating patterns, the interchange between meat consumption dimensions is worth further exploration.

As such, results of this study suggest further research on meat attachment and avoidance is warranted. The results of this study highlight that measuring perceptions on meat consumption reveals generational and socio-economic divides. The centrality of meat consumption in Canada is at once a physiological, psychological, and social construct, so to shift to plant-based, healthier, sustainable diets social constructs need to be challenged frequently for behaviour to change (Spencer et al., 2018). Nonetheless, it appears that a substantial number of consumers have already opted to reduce their meat-eating frequency. The paradoxical presence of flexitarians within a food culture of meat- centred meals and eating patterns in Canada is puzzling. Perhaps, the explanation lies in the growing division between heavy and light consumers of meat. Respondents who eat larger portions of meat more frequently at breakfast, lunch and dinner, or as snacks, compensate for a reduction in the amount of meat consumed by committed flexitarians. Another possibility could be that rebound effects apply. For instance, consumers may compensate for a reduced meat- eating day for more meat the next day. A meat reducing effect of a regular day during the week when meat is not consumed is nullified by an immoderate meat meal the following day. The level of consumption remains the same. Currently, in this regard there are more questions than well-founded answers.

\section{Conclusion}

This study aimed at understanding the interconnectivity between dimensions of meat consumption. The Canadian market for meat-based protein is changing which could have far - reaching effects on industry providers all along the meat supply chain. Commodity groups may consider positioning their product as an ingredient, part of a much larger portfolio of different protein options for consumers. Beef, pork and chicken must coalesce with other more environmentally and healthy options, such as pulses or fish. This study provides evidence that consumers are becoming savvy of the effects of their food choices on social, environmental and health aspects relevant to society at large. Policy is also driving change as federal agencies responsible for food guides around the world are adjusting to a science-based approach over an industry-heavy influenced model. Given the changing marketplace, more research is needed to better appreciate how meat consumption is evolving and how animal proteins are being replaced in consumers' diets.

\section{References}

Apostolidis, C., \& Mcleay, F. (2019). To meat or not to meat? Comparing empowered meat consumers' and anti-consumers' preferences for sustainability labels. Food Quality and Preference, 77, 109-122. https://doi.org/10.1016/j.foodqual.2019.04.008

Bailey, R., Froggatt, A., \& Wellesley, L. (2014). Livestock - Climate Change's Forgotten Sector. Global Public Opinion on Meat and Dairy Consumption. The Royal Institute of 
International Affairs, Chatham House: London. Retrieved from www.chathamhouse.org/sites/files/chathamhouse/field/field_document/20141203LivestockCl imateChangeForgottenSectorBaileyFroggattWellesleyFinal.pdf

Beardsworth, A., \& Bryman, A. (2004). Meat consumption and meat avoidance among young people. British Food Journal, 106(4), 313-327. https://doi.org/10.1108/00070700410529573

de Boer, J., \& Aiking, H. (2011). On the merits of plant-based proteins for global food security: Marrying macro and micro perspectives. Ecological Economics, 70(7), 1259-1265. https://doi.org/10.1016/j.ecolecon.2011.03.001

Buttlar, B., \& Walther, E. (2018). Measuring the meat paradox: How ambivalence towards meat influences moral disengagement. Appetite, 128, 152-158. https://doi.org/10.1016/j.appet.2018.06.011

Buttlar, B., \& Walther, E. (2019). Dealing with the meat paradox: Threat leads to moral disengagement from meat consumption. Appetite, 137, 73-80. https://doi.org/10.1016/j.appet.2019.02.017

Charlebois, S., \& Haratifar, S. (2015). The perceived value of dairy product traceability in modern society: An exploratory study. Journal of dairy science, 98(5), 3514-3525. https://doi.org/10.3168/jds.2014-9247

Charlebois, S., \& Labrecque, J. (2009). Sociopolitical foundations of food safety regulation and the governance of global agrifood systems. Journal of Macromarketing, 29(4), 363-373. https://doi.org/10.1177/0276146709346255

Charlebois, S., Cunningham, C., Caron, I., Music, J., \& Somogyi, S. (2019). A Review of Food Recalls in Canada: A Nationwide Survey. Food Protection Trends, 39(4), 317-325.

Charlebois, S., McCormick, M., \& Juhasz, M. (2016). Meat consumption and higher prices: Discrete determinants affecting meat reduction or avoidance amidst retail price volatility. British Food Journal, 118(9), 2251-2270. https://doi.org/10.1108/BFJ-03-2016-0121

Charlebois, S., Somogyi, S., \& Kirk, S. F. (2019). Fragmented Food Habits and the Disintegration of Traditional Meal Patterns: A Challenge to Public Health Nutrition in Canada?. Journal of International Food \& Agribusiness Marketing, 1-10. https://doi.org/10.1080/08974438.2019.1599750

Charlebois, S., Von Massow, M., \& Pinto, W. (2015). Food recalls and risk perception: An exploratory case of the XL foods and the biggest food recall in canadian history. Journal of Food Products Marketing, 21(1), 27-43. https://doi.org/10.1080/10454446.2013.856055

Curtis, D., Hill, A., Wilcock, A., \& Charlebois, S. (2014). Foodborne and waterborne pathogenic bacteria in selected Organisation for Economic Cooperation and Development (OECD) countries. Journal of food science, 79(10), R1871-R1876. https://doi.org/10.1111/1750-3841.12646

Dagevos, H. (2014). Flexibility in the Frequency of Meat Consumption - Empirical Evidence 
from The Netherlands. EuroChoices, 13(2), 40-45. https://doi.org/10.1111/1746-692X.12062

De Backer, C. J. S., \& Hudders, L. (2015). Meat morals: Relationship between meat consumption consumer attitudes towards human and animal welfare and moral behavior. Meat Science, 99(C), 68-74. https://doi.org/10.1016/j.meatsci.2014.08.011

de Boer, J., Schösler, H., Aiking, H., Environmental Policy Analysis, Chemistry Biology, \& Amsterdam Global Change Institute. (2014). "Meatless days" or "less but better"? Exploring strategies to adapt Western meat consumption to health and sustainability challenges. Appetite, 76, 120-128. https://doi.org/10.1016/j.appet.2014.02.002

De Groeve, B., Bleys, B., \& Hudders, H. (2019). Okay to promote eating less meat, but don't be a cheat - The role of dietary identity, perceived inconsistency and inclusive language of an advocate in legitimizing meat reduction. Appetite, 138, 269-279. https://doi.org/10.1016/j.appet.2019.03.031

Dilworth, T., \& McGregor, A. (2015). Moral Steaks? Ethical Discourses of In Vitro Meat in Academia and Australia. Journal of Agricultural and Environmental Ethics, 28(1), 85-107. https://doi.org/10.1007/s10806-014-9522-y

FAO (Food and Agriculture Organisation of the United Nations) (2012) Sustainable Diets and Biodiversity. www.fao.org/docrep/016/i3004e/i3004e00.htm (accessed 1 February 2018).

Frenette, E., Bahn, O., \& Vaillancourt, K. (2017). Meat, Dairy and Climate Change: Assessing the Long-Term Mitigation Potential of Alternative Agri-Food Consumption Patterns in Canada. Environmental Modeling \& Assessment, 22(1), 1-16. https://doi.org/10.1007/s10666-016-9522-6

Graça, J., Calheiros, M. M., \& Oliveira, A. (2015). Attached to meat? (Un)Willingness and intentions to adopt a more plant-based diet. Appetite, 95(C), 113-125. https://doi.org/10.1016/j.appet.2015.06.024

Graça, J., Godinho, C. A., \& Truninger, M. (2019). Reducing meat consumption and following plant-based diets: Current evidence and future directions to inform integrated transitions. Trends in Food Science \& Technology, 91, 380-390. https://doi.org/10.1016/j.tifs.2019.07.046

Hawkes, N. (2014). Cutting Europe's meat and dairy consumption would benefit health and environment, says report. BMJ: British Medical Journal, 348(Apr25 12), G2949. https://doi.org/10.1136/bmj.g2949

Hildén, M., Jokinen, P., \& Aakkula, J. ( 2012 ). The sustainability of agriculture in a northern industrialized country - from controlling nature to rural development, Sustainability, 4(12), 3387-3403. https://doi.org/10.3390/su4123387

Hughes, G., Kress, K., Armbrecht, E., Mukherjea, R., \& Mattfeldt-Beman, M. (2014). Initial investigation of dietitian perception of plant-based protein quality. Food Science \& Nutrition, 2(4), 371-379. https://doi.org/10.1002/fsn3.112 
Janzen, H. H. (2011) What place for livestock on a re-greening earth? Animal Feed Science and Technology 166-167: 783-796. https://doi.org/10.1016/j.anifeedsci.2011.04.055

Josephine, M. (2018). Sustainable Consumption in Everyday Life: A Qualitative Study of UK Consumer Experiences of Meat Reduction. Sustainability, 10(7). https://doi.org/10.3390/su10072307

Latvala, T., Niva, M., Mäkelä, J., Pouta, E., Heikkilä, J., Kotro, J., \& Forsman-Hugg, S. (2012). Diversifying meat consumption patterns: consumers' self-reported past behaviour and intentions for change, Meat Science, 92(1), 71-77. https://doi.org/10.1016/j.meatsci.2012.04.014

Lentz, C., \& Mirosa, J. (2018). Gauging attitudes and behaviours: Meat consumption and potential reduction. Appetite, 127, 230-241. https://doi.org/10.1016/j.appet.2018.04.015

Mann, N. (2013). Human evolution and diet: A modern conundrum of health versus meat consumption, or is it? Animal Production Science, 53(11), 1135-1142. https://doi.org/10.1071/AN13197

Marija, C., Danijel, K., \& Željka, M. (2011). Consumers' Attitudes towards Farm Animal Welfare and their Influence on Meat Consumption. Agriculturae Conspectus Scientificus (ACS), 76(3), 283-286.

Nasser, R., Cook, S., Bashutski, M., Hill, K., Norton, D., Coleman, J., ... Charlebois, S. (2011). Consumer perceptions of trans fats in 2009 show awareness of negative effects but limited concern regarding use in snack foods. Applied Physiology, Nutrition, and Metabolism, 36(4), 526-532. https://doi.org/10.1139/h11-045

Niemyjska, C., \& Byrka, B. (2018). Too humanlike to increase my appetite: Disposition to anthropomorphize animals relates to decreased meat consumption through empathic concern. Appetite, 127, 21-27. https://doi.org/10.1016/j.appet.2018.04.012

Oates, L., Cohen, M., \& Braun, L. (2012). Characteristics and consumption patterns of Australian organic consumers. Journal of the Science of Food and Agriculture, 92(14), 2782-2787. https://doi.org/10.1002/jsfa.5664

Oh, Canada! Light-life Expands Distribution of Plant Protein Products. (2018). Canada News Wire, p. Canada News Wire, Aug 23, 2018.

Pelletier, N., \& Tyedmers, P. (2010). Forecasting potential global environmental costs of livestock production 2000-2050, Proceedings of the National Academy of Sciences, 107(43), 18371-18374. https://doi.org/10.1073/pnas.1004659107

Pfeiler, E. (2018). Personality and attitudinal correlates of meat consumption: Results of two representative German samples. Appetite, 121, 294-301. https://doi.org/10.1016/j.appet.2017.11.098

Pohjolainen, P., Vinnari, M., \& Jokinen, P. (2015). Consumers' perceived barriers to following a plant-based diet. British Food Journal, 117(3), 1150-1167. 
https://doi.org/10.1108/BFJ-09-2013-0252

Spencer, K., \& Cienfuegos, G. (2018). Student consumer acceptance of plant-forward burrito bowls in which two-thirds of the meat has been replaced with legumes and vegetables: The Flexitarian Flip ${ }^{\mathrm{TM}}$ in university dining venues. Appetite, 131, 14-27. https://doi.org/10.1016/j.appet.2018.08.030

Stranieri, S., Banterle, A., \& Ifamr, I. (2015). Consumer Interest in Meat Labelled Attributes: Who Cares? International Food and Agribusiness Management Review, 18.

Stubbs, R., Scott, S., \& Duarte, C. (2018). Responding to food, environment and health challenges by changing meat consumption behaviours in consumers. Nutrition Bulletin, 43(2), 125-134. https://doi.org/10.1111/nbu.12318

Tobler, C., Visschers, V. H. M., \& Siegrist, M. (2011). Eating green. Consumers' willingness to adopt ecological food consumption behaviors. Appetite, 57(3), 674-682. https://doi.org/10.1016/j.appet.2011.08.010

Verbeke, W. (2015). Profiling consumers who are ready to adopt insects as a meat substitute in a Western society. Food Quality and Preference, 39(C), 147-155. https://doi.org/10.1016/j.foodqual.2014.07.008

Yamamoto, A., Harris, H. R., Vitonis, A. F., Chavarro, J. E., \& Missmer, S. A (2018). A prospective cohort study of meat and fish consumption and endometriosis risk. American Journal of Obstetrics and Gynecology, 219(2), 178.e1-178.e10. https://doi.org/10.1016/j.ajog.2018.05.034

\section{Appendix A: Research Instrument}

Dietary restrictions

1. On average how often do you consume meat or products that include meat?

a. Never

b. Rarely

c. Several times a week

d. Several times a day

2. As a consumer, I consider myself a...

a. Vegetarian (diet free of meat, fish, and fowl flesh)

b. Lacto-ovo vegetarians (diet free of animal flesh but eat eggs and milk products)

c. Vegan (all animal-based products, including honey) 
d. Raw foodists (eat mainly raw fruits, vegetables, legumes, sprouts, and nuts)

e. Flexitarian (vegetarians who occasionally eat meat and fish)

f. Consumer with no dietary preferences

g. Other

3. In the past, have you thought at some point of making any efforts to reduce your personal meat consumption?
a. Yes

b. No

4. On a scale from 1 to 5, how willing would you be to consider reducing your meat consumption sometime in the future?

a. "Not at all willing" to "extremely willing"

5. Specifically, in the next six months do you intend to reduce your meat consumption?

a. "I do not intend at all" to "Fully intend"

6. How important were each of the following factors in influencing your initial decision to lower your overall meat intake?

a. Health benefits (Scale from 1 to 5, "Not important at all" to "Extremely important")

b. More environmentally friendly (Scale from 1 to 5, "Not important at all" to "Extremely important")

c. Animal welfare concerns (Scale from 1 to 5, "Not important at all" to "Extremely important")

d. High cost of meat (Scale from 1 to 5, "Not important at all" to "Extremely important")

e. Taste preferences (Scale from 1 to 5, "Not important at all" to "Extremely important")

f. Weight control (Scale from 1 to 5, "Not important at all" to "Extremely important")

Please indicate whether you agree or disagree with the following statements.

7. To eat meat is one of the great pleasures in life

a. Strongly Agree

b. Somewhat agree

c. Neither agree nor disagree

d. Somewhat disagree

e. Strongly disagree 


\section{Macrothink}

8. I love meals with meat

a. Strongly Agree

b. Somewhat agree

c. Neither agree nor disagree

d. Somewhat disagree

e. Strongly disagree

9. I am a big fan of meat in general

a. Strongly Agree

b. Somewhat agree

c. Neither agree nor disagree

d. Somewhat disagree

e. Strongly disagree

10. A good steak, a piece of chicken or pork are without comparison
a. Strongly Agree
b. Somewhat agree
c. Neither agree nor disagree
d. Somewhat disagree
e. Strongly disagree

11. When I eat meat, I'm reminded of the deaths and suffering of animals
a. Strongly Agree
b. Somewhat agree
c. Neither agree nor disagree
d. Somewhat disagree
e. Strongly disagree

12. To eat meat is disrespectful towards life and the environment
a. Strongly Agree
b. Somewhat agree
c. Neither agree nor disagree
d. Somewhat disagree 


\section{Macrothink}

e. Strongly disagree

13. I feel awful when I think of eating meat
a. Strongly Agree
b. Somewhat agree
c. Neither agree nor disagree
d. Somewhat disagree
e. Strongly disagree

14. Meat reminds me of food recalls and diseases
a. Strongly Agree
b. Somewhat agree
c. Neither agree nor disagree
d. Somewhat disagree
e. Strongly disagree

15. To eat meat is a fundamental right of every person
a. Strongly Agree
b. Somewhat agree
c. Neither agree nor disagree
d. Somewhat disagree
e. Strongly disagree

16. As humans, it is natural to eat meat
a. Strongly Agree
b. Somewhat agree
c. Neither agree nor disagree
d. Somewhat disagree
e. Strongly disagree

17. Eating meat is part of a natural and balanced diet
a. Strongly Agree
b. Somewhat agree
c. Neither agree nor disagree 


\section{Macrothink}
d. Somewhat disagree
e. Strongly disagree

18. I can't see myself eating meat
a. Strongly Agree
b. Somewhat agree
c. Neither agree nor disagree
d. Somewhat disagree
e. Strongly disagree

19. If I don't eat meat, I would get sick or feel weak
a. Strongly Agree
b. Somewhat agree
c. Neither agree nor disagree
d. Somewhat disagree
e. Strongly disagree

20. Meat is replaceable in my diet
a. Strongly Agree
b. Somewhat agree
c. Neither agree nor disagree
d. Somewhat disagree
e. Strongly disagree

21. I know how to replace meat in my diet
a. Strongly Agree
b. Somewhat agree
c. Neither agree nor disagree
d. Somewhat disagree
e. Strongly disagree

22. I consider lab-grown meat as an alternative to regular meat

a. Strongly Agree 


\section{Macrothink}
b. Somewhat agree
c. Neither agree nor disagree
d. Somewhat disagree
e. Strongly disagree

23. I consider insects/bugs as an alternative to regular meat
a. Strongly Agree
b. Somewhat agree
c. Neither agree nor disagree
d. Somewhat disagree
e. Strongly disagree

24. What is your gender?
a. Male (1)
b. Female (2)
c. Other (3)

25. What is your marital status?
a. Single (1)
b. Married (2)
c. Divorced or separated (3)

26. What year were you born?
a. After $1994(1)$
b. From 1980 to 1994 (2)
c. From 1965 to 1979 (3)
d. From 1946 to 1964 (4)
e. Before $1946(5)$

27. How many children live in your household?
a. One (1)
b. Two (2)
c. Three or more (3)
d. None (4) 
28. What is your education level?
a. High School Diploma (1)
b. University Degree (2)
c. Graduate Degree or Diploma (3)
d. Other (4)

29. Which province or region are you from?
a. Ontario (1)
b. Quebec (2)
c. Atlantic (3)
d. Prairies (4)
e. British Columbia (5)
f. Northern Communities (6)

30. Was your household income over the last 12 months?
a. Less than $\$ 40,000$ (1)
b. Between $\$ 40,001$ and $\$ 80,000$ (2)
c. Between $\$ 80,001$ and $\$ 150,000$ (3)
d. More than $\$ 150,001(4)$

\section{Copyright Disclaimer}

Copyright for this article is retained by the author(s), with first publication rights granted to the journal.

This is an open-access article distributed under the terms and conditions of the Creative Commons Attribution license (http://creativecommons.org/licenses/by/4.0/). 